\title{
CLINICAL EVALUATION OF THE USE OF PROCEED MESH IN RECONSTRUCTION OF ORBITAL FLOOR FRACTURES: CLINICAL TRIAL Oraby $\mathrm{M} \mathrm{S}^{1} B D S$, Sharara A $\mathrm{A}^{2} P h D$, Fahmy $\mathrm{M} \mathrm{H}^{2} P h D$
}

\begin{abstract}
:
Introduction: Orbital fracture is a common type of midfacial trauma. Its proper treatment is considered a challenging situation. Otherwise orbital complications; as diplopia, limited ocular motility, enophthalmos, hypoglobus and infraorbital dysesthesia; may occur.

Proceed ${ }^{\circledR}$ mesh consists of polypropylene soft mesh encapsulated with polydioxanone (PDS) and layered with oxidized regenerated cellulose (ORC). It is a widely used mesh in hernia repair which is proved to be safe and suitable. The ORC component provides the mesh with some properties differ from other materials. It provides a physical barrier to decrease the adhesion between the mesh and orbital tissue. It is a commonly used hemostatic agent. In addition, it is proved to be antibacterial against many resistant species. The PDS component attaches the ORC with polypropylene soft mesh.

Objectives: We aimed in this study to evaluate Proceed ${ }^{\circledR}$ mesh clinically in reconstruction of orbital floor defects in seven patients.

Materials and Methods: Indications for intervention were diplopia, enophthalmos, minimal clinical improvement over time under drug therapy, ocular limited motility, dystopia, defect more than $50 \%$ of the orbital floor and progressive infraorbital hypoesthesia. The ORC side of the mesh was placed facing orbital soft tissue, while polypropylene side was placed towards orbital bony wall. The follow-up schedule was 3 days postoperatively then once weekly for two weeks and then monthly for 6 months.

Results: Clinically, most patients recovered from diplopia, dystopia, ocular restriction and enophthalmos. Two patients had transitory postoperative diplopia (for 1 week), that may be due to postoperative muscle weakness. One patient out of four suffered from preoperative ocular restriction, had no or slight improvement postoperatively. Two patients complained from inflammatory reaction within $2-4$ weeks postoperatively, resolved by anti-
\end{abstract} inflammatory and antibiotic administration.

Conclusion: The study concluded that Proceed $®$ mesh is a suitable material for orbital floor reconstruction, especially in cases of small to medium defects $\left(<3 \mathrm{~cm}^{2}\right)$.

Key words: orbital floor, Proceed ${ }^{\circledR}$ mesh, implant material, prolene mesh.

1- Instructor at Department of Oral and Maxillofacial Surgery, Faculty of Dentistry, Alexandria University.

2- $\quad$ Professor at Department of Oral and Maxillofacial Surgery, Faculty of Dentistry, Alexandria University.

\section{INTRODUCTION}

Maxillofacial injuries rate is raising due to the high speed travel as well as increasing violence. Road traffic accident, personal assault, direct/indirect trauma, sport activities, falls, and firearms are considered common causes to facial injuries (1).

Orbital fracture occurs as a result of the application of forces that overcome the resistance of orbital bony structures. It is one of the most frequent fractures following midfacial trauma. Orbital fractures account for $40 \%$ of craniofacial injuries. They represent $21.4 \%$ of midfacial fractures (2-6).

The orbital complications resulted from these fractures may be: diplopia, restriction of ocular motility, enophthalmos, hypoglobus, and infraorbital dysesthesia (7). So proper examination, diagnosis and treatment should be performed in suspected cases. Improper treatment or misdiagnosis of orbital floor fractures may result in permanent diplopia, enophthalmos or nerve dysesthesia (8).

Methods for orbital floor reconstruction have great controversy among the surgeons. The choice of material depends on the size and complexity of the orbital fracture. The ultimate goal for orbital floor repair is to restore function and form in the safest possible way (9).

Although the autogenous bone graft remains the gold standard material for orbital reconstruction; donor site morbidity is considered its major disadvantage. Other disadvantages are altered resorption rate, increased operation time, limited graft size and thickness, and limited ability of contouring $(9,10)$.

Resorbable alloplastic materials are less likely to have late complications such as infection and extrusion. But they have inferior strength, need of overcorrection, lack of osteoconductivity and have late enophthalmos possibility (9, $10)$.

Titanium mesh is a widely used implant material, as it showed success and good results in reconstructing and spanning large defects. On the other hand, it is expensive, needs fixation, not easily contoured and positioned, sharp edges may catch periorbital fat, dense fibrosis occurs within mesh`s pores and difficulty to be removed if needed $(9,10)$.

Prolene mesh is one of the non-resorbable alloplastic materials. Prolene is biocompatible, cheap, strong yet flexible, easy to be contoured and shaped, has unlimited supply and has both tensile strength and stability (11-13).

Proceed ${ }^{\circledR}$ mesh consists of oxidized regenerated 
cellulose (ORC) fabric, and Prolene Soft Mesh which is encapsulated by a polydioxanone polymer (PDS). The polypropylene mesh side of the product allows for tissue ingrowth. The ORC side provides a bioresorbable layer that physically separates the polypropylene mesh from underlying tissue during the wound-healing period, which minimizes periorbital tissue attachment to the mesh. The polydioxanone provides a bond between the ORC layer to polypropylene mesh (14).

Oxidized regenerated cellulose is a widely used hemostatic agent, so it may aid in decreasing of retrobulbar hemorrhage possibility. It also has antimicrobial activity and is effective against antibiotic-resistant microorganisms like Methicillin-resistant Staphylococcus aureus (MRSA) and Methicillin-resistant Staphylococcus epidermidis (MRSE) $(14,15)$.

Our aim in this study was to get the benefits of the combination between these three materials; including reduced adhesions with surrounding tissues, hemostasis and antibacterial properties, in order to overcome the drawbacks of other widely used orbital floor implant materials. So we evaluated this material clinically in cases of orbital floor fractures indicated for surgical repair.

\section{MATERIALS AND METHODS}

It is a prospective observational study during the period from September 2014 to May 2015 including the follow up for 6 months. Seven patients were admitted to the Oral and Maxillofacial Surgery Department, Faculty of Dentistry, Alexandria University; suffering from orbital floor fractures indicated for surgical repair.

Patients suffered from orbital floor fractures; either unilaterally or bilaterally or associated with other maxillofacial injuries were included in the study. Patients were diagnosed by computed tomography (CT) (Figure $1 \mathrm{~A}$ $\&$ B) and evaluated for trauma of the ocular globe by ophthalmologist.

The indications for surgery included impaired eye movement, diplopia more than 7 days, enophthalmos, hypoglobus, radiographically the defect was more than $50 \%$ of orbital floor, progressive infraorbital hypoesthesia and minimal clinical improvement over time under drug therapy.

Our choice was orbital reconstruction with Proceed ${ }^{\circledR} *$ Surgical Mesh. It is composed of oxidized regenerated cellulose (ORC) fabric, and Prolene Soft Mesh; a nonresorbable Polypropylene mesh, which is encapsulated by a Polydioxanone polymer. (Figure 2)

Before the surgical intervention of the orbital fracture, forced duction test was done to examine the limitation. The approach to orbital floor was through an infraorbital incision. After reaching the orbital rim, subperiosteal dissection was performed to visualize the entire orbital fracture. Entrapped soft tissues were freed and repositioned intraorbitally. (Figure 3)

The defect was then measured by metallic ruler and the mesh was tailored and contoured according to the size of the

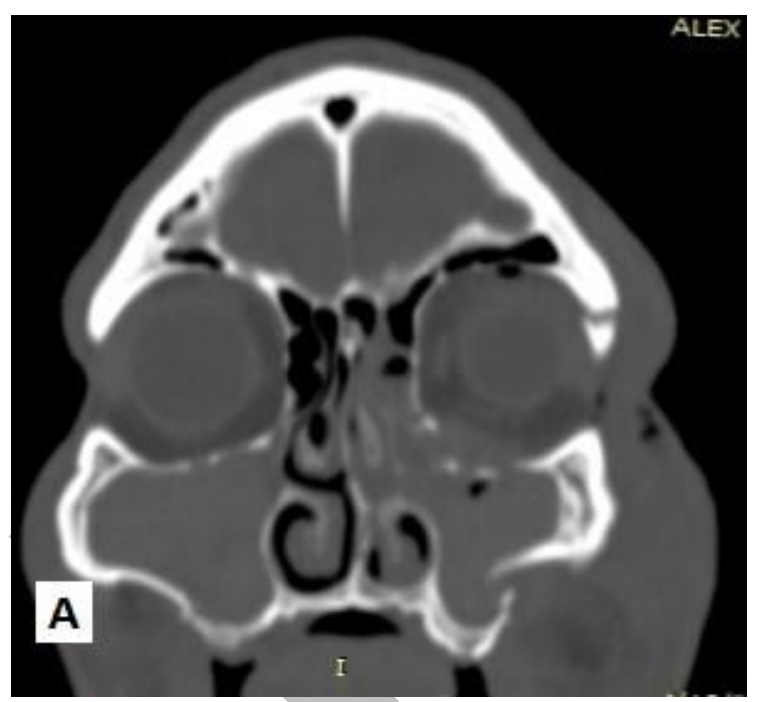

Fig. 1a: Preoperative CT scan showing left orbital floor fracture Coronal view

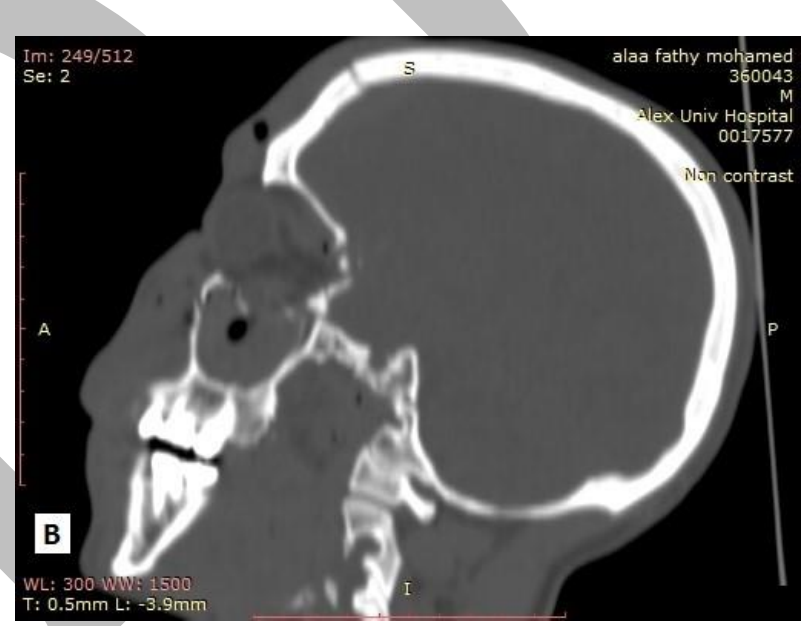

Fig.1b: Sagittal view.

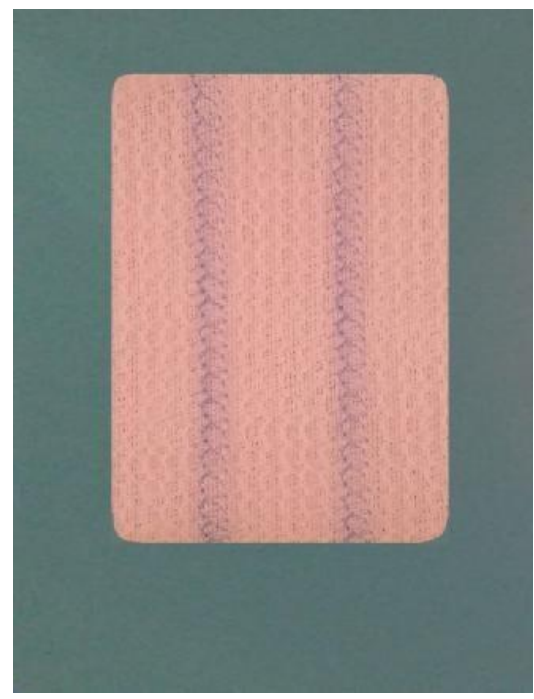

Fig 2: Proceed® mesh (polypropylene soft mesh encapsulated with PDS and layered in one side by ORC) 


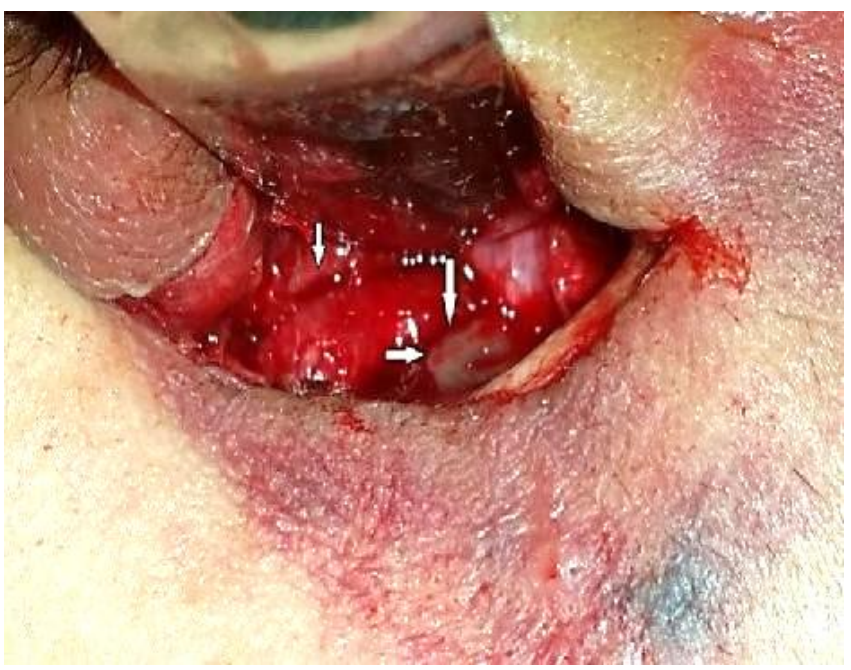

Fig. 3: Photograph showing floor exploration (Arrows: bone boundaries of the defect)

defect. The mesh was folded 2-3 times. Insertion of the Proceed ${ }^{\circledR}$ mesh was done as follows: prolene side of the mesh (the side with blue strea) was facing the orbital bone, while ORC side was toward the periorbital soft tissue. Placement of the mesh was done without fixation. Forced duction test was done to ensure freeing of all herniated soft tissue. Postoperatively patients were evaluated for diplopia, visual acuity, enophthalmos and ocular movement in the ophthalmologic department, faculty of medicine. Clinically, infraorbital sensation was examined subjectively.

\section{RESULTS}

In the present study seven patients (seven males) with age range from 19 to 60 years were included. The causative factors for fractures were road traffic accident in three cases, personal assault in two cases and motorcycle accident in two cases. Early intervention was done (within 2 weeks) in all patients.

In addition to orbital floor fracture, in all seven cases there was associated zygomatico-maxillary complex fracture. There was additional frontal bone fracture in two cases, a case associated with nasal fracture and a case associated with mandibular fracture.

Diplopia was noted in six cases, limitation of ocular motility in four cases, enophthalamos in three cases and ocular dystopia in two cases, ptosis in two cases, epiphora in one case and proptosis in one case.

All seven patients enrolled in the study consented to participate. After orbital floor reconstruction, a clinical evaluation was done to evaluate patients on follow-up visits. All the patients of preoperative diplopia showed significant improvement postoperatively. Two patients complained from transient diplopia postoperatively resolved within one week. One case out of four with preoperative ocular restriction shows no or minimal improvement postoperatively although patient didn't complain from postoperative diplopia.
All patients with preoperative enophthalmos showed improvement in postoperative follow up visits. The two cases of preoperative ocular dystopia showed significant improvement postoperatively. One case out of two with preoperative ptosis showed improvement postoperatively. One case complained from epiphora didn`t improve postoperatively and required ophthalmologic intervention. One case of post-traumatic visual impairment showed some improvement over the follow up visits but not fully recovered. The operated cases with preoperative and postoperative findings were listed in Table 1.

Complications including infection, extrusion, implant migration and retrobulbar hemorrhage did not occur in the current study. Only two out of seven cases complained from late inflammatory reaction (within 2-4 weeks postoperative) and resolved within 4 days by anti- inflammatory and antibiotic administration. (Figures 4 and 5)

\section{DISCUSSION}

Orbital floor reconstruction has been and still a matter of controversy in literature with regard to the indication, timing, surgical technique, access and reconstruction materials used $(11,16)$. Techniques for reconstruction of orbital floor fractures continue to evolve and innovative alloplastic materials have been introduced (9).

In our therapeutic protocol, the indications for orbital floor repair include diplopia, evidence of muscle or perimuscular soft tissue entrapment in $\mathrm{CT}$, minimal clinical improvement over time under drug therapy, progressive infraorbital hypoesthesia, and orbital defects greater than $50 \%$ of the orbital floor with a resultant enophthalmos which is similar to recommendation of Burnstine et al (17).

Prolonged incarceration of orbital content leads to atrophy and scar contracture, which needs compensation of larger degree of soft tissue loss and enlarged orbital volume (10). According to this fact, we reconstructed orbital floor with unresolved clinical findings within 2 weeks.

A variety of implant materials are used in orbital wall reconstruction but no material has yet proven to be successful without any complications. A composite multilayered implant material (Proceed mesh) used for abdominal hernia repair was assessed in this study. Proceed mesh showed no serious complication and application safety in our study as well as in hernia repair according to Rosenberg et al and Eltayeb et al $(18,19)$.

Its composition offers an advantage over the other implant materials. It consists of biodegradable components (ORC and PDS) and non-biodegradable component (prolene soft mesh). So after the biodegradation process, the remained foreign mass is reduced, and that will decrease long term complications of non-resorbable implants (20, 21).

Comparing Proceed lightweight mesh with heavyweight polypropylene mesh, Proceed mesh has less filament and larger pores. Therefore Proceed mesh is weaker than polypropylene. So incorporating of an absorbable component (PDS) is needed to reinforce it and improve its 
handling. Larger pores of Proceed mesh provide optimal handling, increase the fibrovascular incorporation and decrease the thickness of fibrous capsule, resulting in development of flexible scar mesh (16, 18-23).

As well as Proceed mesh, porous hydroxyapatite and porous polyethylene show fibrous ingrowth and complete vascularization in animal model (24). But they show more adhesion and removal difficulty if needed (22). On the other hand, silicone and nylon has smooth surface that does not bond with bone or soft tissue, which explains their high rate of extrusion and migration (4, 25-28).

\begin{tabular}{|c|c|c|c|}
\hline & age & Preopertive findings & Postopertive findings \\
\hline $\begin{array}{c}\text { Case } \\
1\end{array}$ & 33 & $\begin{array}{ll}\text { - } & \text { Diplopia } \\
\text { - } & \text { Ocular dystopia } \\
\text { - } & \text { ION } \\
& \text { parasthesia. }\end{array}$ & $\begin{array}{l}\text { Improvement of all } \\
\text { preopertive findings. }\end{array}$ \\
\hline $\begin{array}{c}\text { Case } \\
2\end{array}$ & 35 & $\begin{array}{ll}\text { - } & \text { Diplopia } \\
\text { - } & \text { Ocular limitation } \\
\text { - } & \text { Ptosis } \\
\text { - } & \text { ION } \\
& \text { parasthesia. }\end{array}$ & $\begin{array}{ll}\text { - } & \text { Improvement in } \\
\text { diplopia (within } \\
\text { 1week postopertively) } \\
\text { - } & \text { no or slight } \\
\text { improvement in ocular } \\
\text { restriction } \\
\text { - } \\
\text { no improvement in } \\
\text { ptosis }\end{array}$ \\
\hline $\begin{array}{c}\text { Case } \\
3\end{array}$ & 22 & \begin{tabular}{ll} 
- & Diplopia \\
- & \multicolumn{1}{c}{ Enophthalamo } \\
us. \\
- & Ocular dystopia \\
- & Epiphora \\
- & ION \\
& parasthesia.
\end{tabular} & $\begin{array}{l}\text { Improvement of all } \\
\text { preopertive findings } \\
\text { except epiphora and ION } \\
\text { parasthesia }\end{array}$ \\
\hline $\begin{array}{c}\text { Case } \\
4\end{array}$ & 24 & $\begin{array}{ll}\text { - } & \text { Diplopia } \\
\text { - } & \\
& \text { Enophthalamo } \\
\text { us }\end{array}$ & $\begin{array}{l}\text { Improvement of all } \\
\text { preopertive findings }\end{array}$ \\
\hline $\begin{array}{c}\text { Case } \\
5\end{array}$ & 60 & $\begin{array}{ll}- & \text { Proptosis } \\
\text { - } & \text { Ptosis } \\
\text { - } & \text { Visual } \\
& \text { impairment } \\
\text { - } & \text { Ocular limitation } \\
\text { - } & \text { ION } \\
& \text { parasthesia. }\end{array}$ & $\begin{array}{l}\text { Improvement of all } \\
\text { preopertive findings except } \\
\text { visual impairement not fully } \\
\text { recovered. }\end{array}$ \\
\hline $\begin{array}{c}\text { Case } \\
6\end{array}$ & 30 & $\begin{array}{ll}\text { - } & \text { Diplopia } \\
\text { - } & \text { Ocular limitation } \\
\text { - } & \text { ION } \\
& \text { parasthesia. }\end{array}$ & $\begin{array}{l}\text { Improvement of all } \\
\text { preopertive findings. } \\
\text { (diplopia recovered within } \\
1 \text { week postopertively) }\end{array}$ \\
\hline $\begin{array}{c}\text { Case } \\
7\end{array}$ & 19 & $\begin{array}{ll}\text { - } & \text { Diplopia. } \\
\text { - } & \text { Enophthalmos } \\
\text { - } & \text { ION } \\
& \text { paresthesia. } \\
\text { - } & \text { Ocular limitation. }\end{array}$ & $\begin{array}{l}\text { Improvement of all } \\
\text { preopertive findings }\end{array}$ \\
\hline
\end{tabular}

Table 1: Summary of pre and postoperative clinical findings.
Oxidized regenerated cellulose layer has proven to be bactericidal against a broad range of gram-positive and gram-negative organisms including various antibiotic resistant bacteria (MRSA, VRE, PRSP and MRSE) $(14,29)$. The alloplastic implants are more liable to infection than autogenous grafts. This is due to the bacterial load required to infect an alloplastic implant is lowered by a factor of

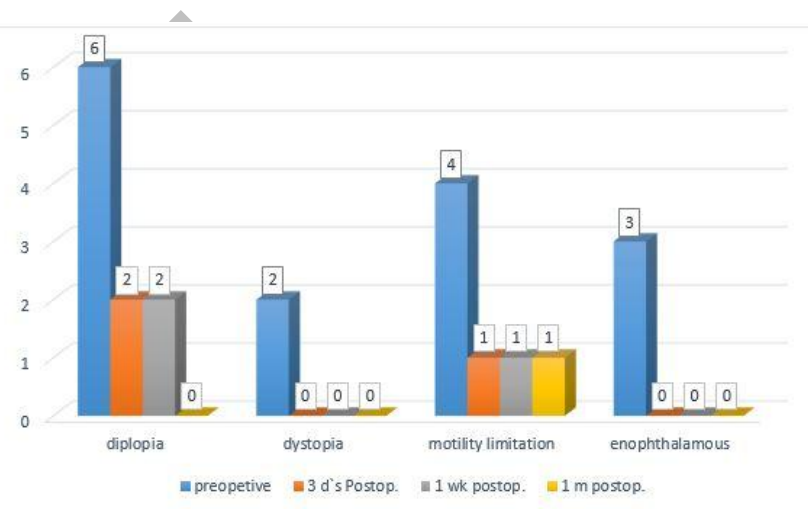

Fig. 4: Graph showing number of patients with pre- and postoperative findings.
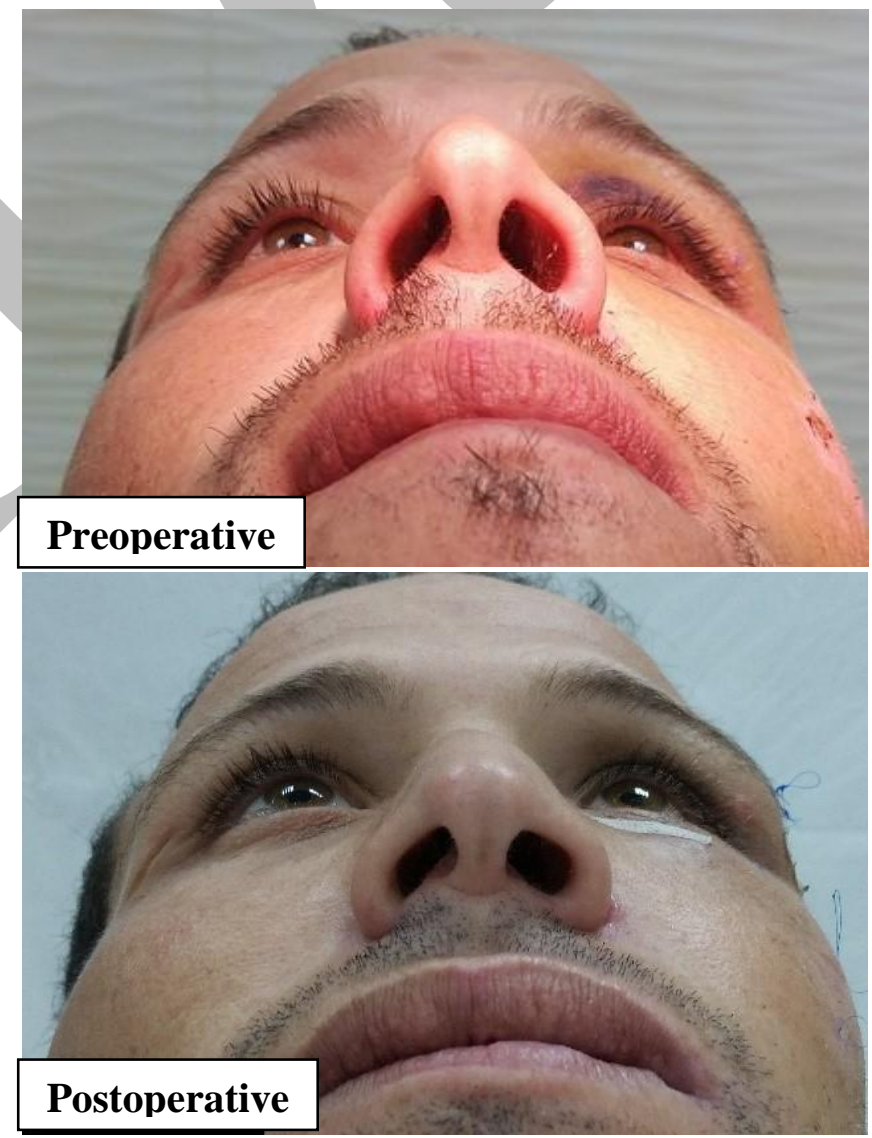

Fig. 5: Photographs showing inferior view for evaluation of enophthalmos. Preoperative enophthalamous in Lt. eye and postoperative improvement in Lt. eye. 
10,000 than for an autogenous graft (30). So the presence of ORC with polypropylene decreases rate of infection lower than other alloplastic materials. This is helpful because orbital floor defects are communicated with maxillary sinuswhich represents a source of infection. Also regarding to infection, in vitro study supported that the infection rate with the porous materials was less than non-porous material (31).

Placement of ORC side facing the orbital soft tissue decreases but not prevent the adhesions between the mesh and the orbital soft tissue. Harrell AG et al (32), have evaluated the adhesion formation of intra-abdominal prosthetics in a rabbit model. They found that polypropylene mesh alone formed more adhesions with greater tenacity than Proceed mesh. Lee and Nunner (33) reported 10 patients of orbital adherence syndrome as a result of using titanium mesh. The usage of ORC as a barrier over titanium mesh could lower adhesion and subsequent fibrosis especially in large defects.

Rubin et al (34) contraindicated orbital floor reconstruction with porous polyethylene implants if the extraocular muscles are visualized during the orbital floor exploration. This is due to the ingrowth of extraocular muscle`s tissues into porous polyethylene implant may result in limiting the duction of the globe because of adhesions. Villarreal et al (35) recommended in this situation the interposition of a smooth nonporous alloplastic implant, or an autogenous nasal septal cartilage between the orbital tissue and the implant to avoid direct contact of the implant with the extraocular muscles. Choi et al (36) supported in their study the efficacy of porous polyethylene implant with barrier in reducing soft tissue adhesions, without compromising the degree of fibrovascular ingrowth into the implant. They recommend it in cases with exposed extraocular muscles. Our mesh offers this combination and could be beneficial in such cases as it contains the resorbable ORC.

Concerning Proceed handling, it can be cut and tailored easily by scissors without unraveling or leaving sharp edges. So it overcomes the problem of cutting titanium mesh and the sharp edges formed if not probably trimmed (37). Once Proceed mesh is trimmed outside the orbit, it maintains its shape and facilitates easily implantation. In comparison to Prolene mesh, Proceed mesh found to be more malleable, with softer borders and has less recoil memory. On the other hand, the ORC component hinders the ability of repetitive trial as it softens once it contacts the blood. So a template of Prolene mesh was used to transfer the size and contour needed to the Proceed mesh.

No further securing (with screws or suture) was necessary. As the intraorbital content is allowed to fall back onto the mesh and the periosteum is closed at the orbital rim. This provides a barrier which prevents the anterior migration (38).

All the patients of preoperative diplopia showed significant improvement postoperatively. Two patients complained from transient diplopia postoperatively which resolved within 1 week. That may be due to surgically induced muscle weakness.

One case out of four, with preoperative ocular restriction, showed no or minimal improvement postoperatively. Although this patient did not complain from postoperative diplopia. We supposed that the patient has strabismus from before.

All patients with preoperative enophthalmos showed improvement in postoperative follow up visits. The two cases of preoperative ocular dystopia showed significant improvement postoperatively. One case out of two with preoperative ptosis showed improvement postoperatively. One case complained from epiphora did not improve postoperatively and required ophthalmologic intervention. One case of post-traumatic visual impairment is showing increasingly improvement over the follow up visits but not fully recovered.

In two patients, inflammation occurs from 2-4 weeks postoperatively. This may be due to the degradation process of ORC and PDS. The inflammation resolved within 4 days after administration of anti-inflammatory and antibiotic therapy. Mauriello et al (39) also found local inflammatory reaction after use of Vicryl (polyglactin-910) mesh implant for repair of orbital floor fracture.

The main disadvantage of this mesh is that it is not radiodense. Therefore its position cannot be easily visualized on immediate postoperative CT scans. It is not easily available, sterilized only with radioactive cobalt, and considered more expensive than Prolene mesh. Aramayo AL et al (40) showed that Proceed mesh may produce acute inflammatory reaction more than Prolene mesh.

The Proceed double-sided mesh is a good surgical option to replace missing bone in the reconstruction of the internal orbital wall especially with visualized extraocular muscle. It is considered biocompatible, easily contoured, allows fibrovascular ingrowth, decrease adhesion, antibacterial and hemostatic. In addition to the advantages of alloplastic material, which are decreased operative time, no donor site morbidity, and the ability to adjust the volume of filling as needed.

\section{CONCLUSIONS}

We concluded from this study that Proceed mesh has a potential to be a useful reconstructive material in orbital floor defects (less than $3 \mathrm{~cm}^{2}$ ). It offers advantages of adhesion reduction, hemostasis and antibacterial component.

\section{ACKNOWLEDGEMENT}

The authors want to acknowledge Dr. Mohamed Farouk Mekky for his scientific contribution in this study.

\section{CONFLICT OF INTEREST}

The authors declare that they have no conflicts of interest. 


\section{REFERENCES}

1. Natu SS, Pradhan H, Gupta H, Alam S, Mohammad S, Pradhan R, et al. An epidemiological study on pattern and incidence of mandibular fractures. Plast Surg Int 2012; 2012: 834364.

2. Reyes JM, Vargas MFG, Rosenvasser J, Arocena MA, Medina AJ, Funes J. Classification and epidemiology of orbital fractures diagnosed by computed tomography. Rev Argent Radiol 2013; 77:139-46.

3. Michael B. Salin BMS. Diagnosis and treatment of midface fractures. In: Fonseca WR (ed). Oral and Maxillofacial Trauma. 3rd ed. Ch 21. Elsevier, 2005. p. 671-2.

4. Baino F. Biomaterials and implants for orbital floor repair. Acta biomaterialia 2011;7:3248-66.

5. Scherer M, Sullivan WG, Smith DJ Jr, Phillips LG, Robson MC. An analysis of 1,423 facial fractures in 788 patients at an urban trauma center. J Trauma 1989; 29: 388-90.

6. Piombino P, Iaconetta G, Ciccarelli R, Romeo A, Spinzia A, Califano L. Repair of orbital floor fractures: our experience and new technical findings. Craniomaxillofac Trauma Reconstr 2010; 3: 217-22.

7. Tang DT, Lalonde JF, Lalonde DH. Delayed immediate surgery for orbital floor fractures: Less can be more. Can J Plast surg 2011; 19: 125-8.

8. Folkestad, Lena. Orbital floor fractures- aspects of diagnostic methods, treatment and sequelae. P.h.D Thesis. Institute of Clinical Sciences, Sahlgrenska Academy, Göteborg University. 2006.

9. Avashia YJ, Sastry A, Fan KL, Mir HS, Thaller SR. Materials used for reconstruction after orbital floor fracture. J Craniofac Surg 2012; 23:1991-7.

10. Schendel SA. The Orbit, An Issue of Oral and Maxillofacial Surgery Clinics. 1st ed. London: Elsevier Health Sciences, 2012.

11. Bhatnagar S, Khare P. Reconstruction of orbital floor fracture using porous polyethylene mesh.Int $\mathrm{J}$ Med Res Rev 2014; 2: 1.

12. Shetty P, Senthil Kumar G, Baliga M, Uppal N. Options in orbital floor reconstruction in blowout fractures: a review of ten cases. J Maxillofac Oral Surg 2009; 8: 137-40.

13. Thorne $\mathrm{CH}$, Gurtner GC. Grabb and Smith's plastic surgery: Lippincott Williams \& Wilkins, 2013.

14. Spangler D, Rothenburger S, Nguyen $K$, Jampani $\mathrm{H}$, Weiss $\mathrm{S}$, Bhende $\mathrm{S}$. In vitro antimicrobial activity of oxidized regenerated cellulose against antibiotic-resistant microorganisms. Surg Infect 2003; 4: 255-62.

15. Ethicon. SURGICEL ${ }^{\circledR}$ Family of Absorbable Hemostats ETHICON 360 [Internet].Available at: http://www.ethicon360.com/products/surgicelfamily-absorbable-hemostats.

16. Mok D, Lessard L, Cordoba C, Harris PG, Nikolis A. A review of materials currently used in orbital floor reconstruction.Can J Plast Surg. 2004; 12:134.

17. Burnstine MA. Clinical recommendations for repair of isolated orbital floor fractures.Ophthalmology 2002; 109:1207-10.

18. Rosenberg J, Burcharth J. Feasibility and outcome after laparoscopic ventral hernia repair using Proceed mesh. Hernia. 2008; 12:453-6.

19. Eltayeb AA, Ibrahim IA, Mohamed MB. The use of PROCEED mesh in ventral hernias: A pilot study on 22 cases. Afr J Paediatr Surg 2013; 10:217.

20. Doctor HG. Evaluation of various prosthetic materials and newer meshes for hernia repairs.J Minim Access Surg 2006; 2:110-6.

21. Deeken CR, Abdo MS, Frisella MM, Matthews BD. Physicomechanical evaluation of absorbable and nonabsorbable barrier composite meshes for laparoscopic ventral hernia repair. Surg Endosc 2011; 25:1541-52.

22. Rubin JP, Yaremchuk MJ. Complications and toxicities of implantable biomaterials used in facial reconstructive and aesthetic surgery: a comprehensive review of the literature. Plast Reconstr Surg. 1997; 100:1336-53.

23. Conze J, Kingsnorth AN, Flament JB, Simmermacher R, Arlt G, Langer $\mathrm{C}$, et al. Randomized clinical trial comparing lightweight composite mesh with polyester or polypropylene mesh for incisional hernia repair. Br J Surg 2005; 92:1488-93.

24. Rubin PA, Popham JK, Bilyk JR, Shore JW. Comparison of fibrovascular ingrowth into hydroxyapatite and porous polyethylene orbital implants. Ophthal Plast Reconstr Surg.1994; 10:96103.

25. Nicholson DH, Guzak SV, Jr. VIsual loss complicating repair of orbital floor fractures.Archives of Ophthalmology. 1971; 86:369-75.

26. Brown AE, Banks P. Late extrusion of alloplastic orbital floor implants. British Journal of Oral and Maxillofacial Surgery. 1993; 31:154-7.

27. Davis RM. Late orbital implant migration. Ann Ophthalmol. $1986 ; 18: 223-4$.

28. Dougherty WR, Wellisz T. The natural history of alloplastic implants in orbital floor reconstruction: an animal model. J Craniofac Surg. 1994 ;5:26-32.

29. Dineen P. The effect of oxidized regenerated cellulose on experimental infected splenotomies. J Surg Res 1977; 23:114-6.

30. Nguyen P.N. SP. Advances in the management of orbital fractures. Clin Plast Surg 1992;19:87-98. 
31. Nunery WR, Tao JP, Johl S. Nylon foil "wraparound" repair of combined orbital floor and medial wall fractures. Ophthal Plast Reconstr Surg 2008; 24:271-5

32. Harrell AG, Novitsky YW, Peindl RD, Cobb WS, Austin CE, Cristiano JA, et al.Prospective evaluation of adhesion formation and shrinkage of intra-abdominal prosthetics in a rabbit model. Am Surg. 2006; 72:808-13.

33. Lee HBH, Nunery WR. Orbital Adherence Syndrome Secondary to Titanium ImplantMaterial. Ophthal Plast Reconstr Surg 2009; 25:33-6.

34. Rubin P, Bilyk J, Shore J. Management of orbital trauma: fractures, hemorrhage, and traumatic optic neuropathy. Am Acad Ophthalmol Focal Points 1994; 7:1-8.

35. Villarreal PM, Monje F, Morillo AJ, Junquera LM, González C, Barbón JJ. Porous polyethylene implants in orbital floor reconstruction. Plast Reconstr Surg. 2002; 109:877-85.

36. Choi JC, Bstandig S, Iwamoto MA, Rubin PA, Shore JW. Porous polyethylene sheet implant with a barrier surface: a rabbit study. Ophthal Plast Reconstr Surg. 1998; 14:32-6.

37. Janecka IP. New reconstructive technologies in skull base surgery: role of titanium mesh and porous polyethylene. Archives of otolaryngology-head \& neck surgery. 2000

38. Mar;126:396-401.Bilyk JR, Rubin PAD, Shore JW. Correction of Enophthalmos with Porous Polyethylene Implants. Int Ophthalmol Clin 1992; 32:151-6.

39. Mauriello JA, Jr., Wasserman B, Kraut R. Use of Vicryl (polyglactin-910) mesh implant for repair of orbital floor fracture causing diplopia: a study of 28 patients over 5 years. Ophthal Plast Reconstr Surg. 1993;9:191-5.

40. Aramayo ALG, Lopes Filho GdJ, Barbosa CdA, Amaral VdF, Costa LA. Abdominal wall healing in incisional hernia using different biomaterials in rabbits. Acta Cir Bras2013;28:307-16. 